\title{
Imaging-based coculture model for high-throughput compound screening in hematological cancers
}

Sophie A. Herbst ${ }^{1-5^{*}}$, Vladislav Kim ${ }^{2,3,5^{*}}$, Eva C. Schitter ${ }^{1}$, Peter-Martin Bruch ${ }^{1-3}$, Tobias Roider $^{1-3}$, Nora Liebers ${ }^{1-4}$, Carolin Kolb ${ }^{1}$, Mareike Knoll ${ }^{1}$, Junyan Lu $^{2,3}$, Peter Dreger ${ }^{1}$, Carsten Müller-Tidow ${ }^{1-3}$, Thorsten Zenz ${ }^{6}$, Wolfgang Huber ${ }^{2,3 \S}$, Sascha Dietrich ${ }^{1-4 \S}$

\author{
Affiliations: \\ 1 Department of Medicine V, Hematology, Oncology and Rheumatology, University of Heidelberg, \\ Heidelberg, Germany \\ 2 European Molecular Biology Laboratory (EMBL), Heidelberg, Germany \\ 3 Molecular Medicine Partnership Unit (MMPU), Heidelberg, Germany \\ 4 Department of Translational Medical Oncology, National Center for Tumor Diseases (NCT) Heidelberg \\ and German Cancer Research Center (DKFZ), Heidelberg, Germany \\ 5 Faculty of Biosciences, University of Heidelberg, Heidelberg, Germany \\ 6 Department of Medical Oncology and Hematology, University Hospital Zürich, Zürich, Switzerland
}

* These authors contributed equally

$\S$ These senior authors contributed equally

Character count abstract: 1220

Character count complete manuscript:

\section{Abstract}

The bone marrow microenvironment modulates treatment response in blood cancers but a systematic assessment of anticancer drug effects in the context of this protective niche has been missing. To fill this gap, we established an ex-vivo model that enables high-throughput compound screening in leukemia-stroma coculture. We applied 50 compounds to 108 patient samples with hematological malignancies in monoculture and coculture with bone marrow stromal cells and measured cellular phenotypes via automated confocal microscopy. Stromal coculture conferred resistance to $52 \%$ of compounds in chronic lymphocytic leukemia (CLL) and to $36 \%$ of compounds in acute myeloid leukemia (AML). Although a partial loss in efficacy was observed for a considerable number of investigated drugs, responses to many of the drugs were comparable between mono- and cocultures. This suggests that large-scale monoculture drug perturbation studies might be sufficient for the purpose of first-line screening. However, our study also uncovered a substantial heterogeneity of stromal protection across the probed samples and compounds, which highlights the importance of validating the findings of monoculture screens in stroma coculture models.

\section{Introduction}

Ex-vivo compound screening assays are powerful tools for basic cancer research and precision oncology. They can provide a better understanding of the phenotypic and molecular heterogeneity of a disease (Barretina et al. 2012; Garnett et al. 2012; Pemovska et al. 2013; Tyner et al. 2013; Basu et al. 2013; lorio et al. 2016; Dietrich et al. 2018; Lu et al. 2021) and even support clinical decision making by suggesting personalized treatment options for individual patients (Snijder et al. 2017; Liebers et al. 2019; Kornauth et al. 2021). 
bioRxiv preprint doi: https://doi.org/10.1101/2022.02.18.481065; this version posted February 20, 2022. The copyright holder for this preprint (which was not certified by peer review) is the author/funder, who has granted bioRxiv a license to display the preprint in perpetuity. It is made available under aCC-BY-NC-ND 4.0 International license.

However, one of the biggest open questions with such ex-vivo assays is to what extent a limited representation of the tumor microenvironment affects a model's validity, since microenvironment interactions and stimuli can greatly affect a cancer cell's dependencies and vulnerabilities.

Deprived of microenvironment signals, leukemia cells undergo spontaneous apoptosis ex vivo (Collins et al. 1989; Bendall et al. 1994), which can be alleviated by the addition of bone marrow stromal cells (Bendall et al. 1994; Panayiotidis et al. 1996; Lagneaux et al. 1998). Coculture studies (Konopleva et al. 2002; Kurtova et al. 2009) revealed that the bone marrow stroma protects leukemia cells from drug-induced apoptosis. Such protection may lead to residual disease (Burger \& O'Brien, 2018) and emergence of resistant clones (Ten Hacken \& Burger, 2016). Coculture models have been used to approximate the effects of the microenvironment and to validate drug response results obtained in monoculture (Kurtova et al. 2009; Moffat et al. 2014; Horvath et al. 2016; Cucchi et al. 2020). However, the validity of coculture models has not been tested rigorously, and current evidence is limited to a scarce number of compounds probed in small-scale coculture studies (Panayiotidis et al. 1996; Mudry et al. 2000; Konopleva et al. 2002; Kurtova et al. 2009; Zeng et al. 2009; Vianello et al. 2010; Zhang et al. 2012; Nwabo Kamdje et al. 2012; Gupta et al. 2013; Quintarelli et al. 2014; Karjalainen et al. 2017; Ding et al. 2018; Zhang et al. 2019).

There are several approaches for modeling the leukemia microenvironment. The soluble bone marrow microenvironment can be modelled ex vivo by adding conditioned medium from stromal cells (Schulz et al. 2011; Bergfeld et al. 2014) or by combining stroma-secreted cytokines with compound perturbations (Bruch et al, 2021). In addition to soluble factor exchange, direct physical contact with stromal cells promotes the survival of leukemia cells in the bone marrow (Dubois et al, 2020). To mimic the effects of both soluble and physical bone marrow microenvironment, we used an ex-vivo coculture system with leukemia and bone marrow stromal cells.

For many antileukemic drugs, the extent to which the bone marrow microenvironment interferes with the drug activity remains unknown. Therefore, we performed a large-scale study comparing compound efficacy in leukemia monoculture and leukemia-stroma coculture. While most of the previous studies (Barretina et al. 2012; Basu et al. 2013; Pemovska et al. 2013; Dietrich et al. 2018) utilized ATP-based assays to quantify viability, we used imaging-based screening that enabled us additionally to investigate the relationship between drug response and spontaneous apoptosis in mono- and coculture. Furthermore, we leveraged the power of imaging-based profiling (Perlman et al. 2004; MacDonald et al. 2006; Loo et al. 2007; Bray et al. 2016) to characterize drug effects and identify cellular changes due to the stromal environment and drug treatments.

\section{Results}

\section{Imaging-based compound screen in leukemia-stroma coculture}

We established a microscopy-based system for compound screening in primary blood cancer cells cocultured with the HS-5 bone marrow stromal cell line (see Materials and Methods). Using this platform, we screened 50 compounds at 3 concentrations (Supplementary Table 1) in 108 leukemia and lymphoma samples (Supplementary Tables 2- 
3) in mono- and coculture (Fig. 1A), including chronic lymphocytic leukemia (CLL, $n=81$ ), acute myeloid leukemia ( $A M L, n=17$ ), T-cell-prolymphocytic leukemia (T-PLL, $n=4$ ), mantle cell lymphoma (MCL, $n=4)$ and hairy cell leukemia $(H C L, n=2)$.

We used confocal microscopy to determine viability and morphological changes in leukemia cells (see Materials and Methods). Nuclei and lysosomal compartments were stained in all samples. In non-CLL entities, we used the same palette as in CLL with an additional channel (Calcein, green) staining the cytoplasm of viable cells. In CLL, viable cells were identified based on nucleus area, which was also used for distinguishing CLL and stromal nuclei. In non-CLL entities, we trained a machine learning model to distinguish leukemia cells from stromal cells in coculture images (see Materials and Methods and Supplementary Fig. S1 AB).

Our primary assay readout was viability, defined as the viable fraction of leukemia cells. Viabilities in drug-treated wells were normalized relative to viabilities in untreated wells to adjust for spontaneous apoptosis (see Materials and Methods). The viability readout was highly reproducible with replicate correlations of $r>0.7$ (Supplementary Fig. S1 C). Additionally, we measured morphological features describing nucleus and cell shape as well as lysosomal activity. We used only reproducible morphological properties with replicate correlations $r>0.5$ (see Materials and Methods and Supplementary Fig. S2).

First, we investigated the impact of the bone marrow microenvironment on unperturbed leukemia and lymphoma cells. We observed several morphological changes in coculture. In AML, a joint 2D-embedding of viable leukemia cells based on their morphological properties (see Materials and Methods) revealed the separation of mono- and coculture leukemia cell populations (Fig. 1B). In particular, we found increased calcein eccentricity and convex area of AML and T-PLL cells in coculture (Fig. 1C and Supplementary Fig. S3 A), which suggests that cells of these disease entities generally take on more elongated shapes in the presence of stromal cells. For the B-cell diseases, MCL and CLL, no dramatic changes in morphology were observed (Fig. 1C). Only a modest increase in nucleus eccentricity was detected in most CLL samples (Supplementary Fig. S3 B).

\section{Stromal protection increases viability of blood cancer cells}

We used median viability of untreated wells to assess the degree of spontaneous apoptosis. In monoculture, proportions of viable leukemia cells in the absence of drug treatment were highly variable, ranging from $10 \%$ to over $90 \%$ (Fig. $2 \mathrm{~A}$ ). Interestingly, the samples with low monoculture viability ( $<50 \%$ alive cells) showed the highest increase in viability in coculture (Fig. 2A), reflecting their stronger dependence on the microenvironment signals.

Spontaneous apoptosis rates varied not only across individual samples but also based on the well position on a microwell plate (Fig. 2B). In monoculture, untreated wells on the plate edge had consistently lower viabilities than those in the central part of the plate. The edge effect was reduced in coculture, in which no positional variation was observed (Fig. 2B).

\section{Degree of stromal protection varies across probed compounds}

We measured leukemia and lymphoma cell viability after ex-vivo drug exposure and compared normalized viabilities in mono- and coculture for each compound using a paired ttest. Twenty-six (52\%) compounds in CLL-stroma coculture and eighteen (36\%) compounds in AML-stroma coculture showed a significant reduction in efficacy (Fig. $3 A$ and 
bioRxiv preprint doi: https://doi.org/10.1101/2022.02.18.481065; this version posted February 20,2022 . The copyright holder for this preprint (which was not certified by peer review) is the author/funder, who has granted bioRxiv a license to display the preprint in perpetuity. It is made available under aCC-BY-NC-ND 4.0 International license.

Supplementary Table 4). Quantitative assessment of drug efficacy changes in coculture revealed similar patterns in AML and CLL (Supplementary Fig. S4).

In line with the previously reported findings (Kurtova et al, 2009; Konopleva et al, 2002; Mudry et al, 2000; Kay et al, 2007; Mraz et al, 2011; Zhang et al, 2012), chemotherapeutics were less effective in coculture than in monoculture. The three chemotherapeutics fludarabine, doxorubicin and cytarabine showed a decreased efficacy in cocultures of CLL and of AML, suggesting a similar resistance mechanism in different leukemias entities (Fig. 3A). For fludarabine (Fig. 3B), we reproduced stroma-mediated protection against druginduced apoptosis in cocultures of CLL cells and primary mesenchymal stromal cells (MSCs), which unlike HS-5 cells have not undergone immortalisation and were subjected only to a limited time of ex-vivo culturing. Additionally, proteasome inhibitors carfilzomib and ixazomib and BET inhibitors JQ1 and I-BET-762, showed significantly reduced efficacy in CLL and AML cocultures (Fig. 3A). We confirmed the decreased activity of JQ1 in CLL coculture with primary MSCs (Fig. 3C).

A considerable proportion of drugs had an unchanged efficacy in CLL (44\%) and AML (58\%) cocultures (Fig. $3 \mathrm{~A}$ and Supplementary Table 4). Some clinically relevant drugs such as BCR-Abl/Src inhibitor dasatinib, FLT3 inhibitor quizartinib, CDK inhibitor palbociclib (Fig. 3A) maintained their efficacy in coculture. Additionally, a number of experimental compounds such as Mdm2 inhibitor nutlin 3a, BH3 mimetics obatoclax mesylate and UMI-77, Akt inhibitor MK2206, and NFkB inhibitors EVP4593 and BAY11-7085 showed no significant reduction of efficacy in coculture (Fig. $3 A$ ). These results suggest that the bone marrow microenvironment selectively influences the efficacy of many but not all compounds.

Bone marrow stroma secretes pro-survival signals, such as the cytokine CXCL12, which binds to the CXCR4 receptor (Dubois et al, 2020). Plerixafor, a CXCR4 antagonist, showed a small increase in efficacy in CLL and AML coculture (Fig. 3A). Although this effect was not statistically significant in our data, plerixafor has previously been shown to overcome stromamediated resistance (Uy et al, 2012; Sison et al, 2014).

The JAK inhibitors tofacitinib and ruxolitinib were the only compounds in the screen that were more effective in both CLL and AML coculture than in monoculture (Fig. 3A). We validated the increase in sensitivity to tofacitinib and ruxolitinib in CLL coculture with primary MSCs (Fig. 3D,E). The presence of bone marrow stromal cells increased phosphorylation of STAT3 at Tyr705 in CLL cells, which was reversed by JAK inhibition (Supplementary Fig. S5 A). The conditioned medium from HS-5 stromal cells or MSCs was sufficient to increase STAT3 phosphorylation (Supplementary Fig. S5 B), suggesting that the JAK-STAT-mediated protection is based on the exchange of soluble factors. This highlights the importance of targeting components of the soluble microenvironment for disrupting the interaction between stromal and leukemia cells.

\section{Coculture recapitulates most clinically established drug-gene associations}

We used 80 CLL samples with genetic information (see Materials and Methods) to identify drug-gene associations in mono- and coculture. For each drug-gene pair we performed a $t-$ test, comparing drug responses in mutated and wildtype groups (see Fig. 4A and Supplementary Table 6). The $t$-statistic values in mono- and coculture are shown in Fig. 4B, with significant associations (FDR $<0.1)$ highlighted. 
Overall, the direction of drug-gene associations was preserved in CLL coculture (Supplementary Fig. S6), with only one significant association reversed. Generally, effect size estimates of drug-gene associations in coculture were lower than in monoculture. In particular, associations of BCR inhibitors with IGHV mutational status and trisomy 12 exhibited smaller effect sizes in CLL coculture than in monoculture (Fig. 4C). Consequently, some well-established associations, such as the increased sensitivity of the U-CLL group to ibrutinib (Guo et al, 2016; Dietrich et al, 2018), were detected only in monoculture (Fig. 4A and Supplementary Table 6).

Stromal protection from BCR inhibitors was stronger in U-CLL samples than in M-CLL samples (Fig. 4D). Trisomy12-positive samples treated with BCR inhibitors were also more strongly protected by the stroma microenvironment than trisomy-negative samples (Fig. 4D). Higher viability gain observed in U-CLL and trisomy12-positive samples (Fig. 4D) dampened BCR inhibitor associations, leading to decreased effect sizes in coculture (Fig. 4C).

Coculture reduced not only effect size estimates but also the drug response variability of many compounds (Fig. 4E). For some drug-gene associations, variance reduction in coculture offset the decrease in effect size. For instance, nutlin 3a - TP53 and proteasome inhibitor associations with del11q were enhanced in coculture (Fig. 4B and Supplementary Table 6). However, despite reduced technical variation the number of discovered drug-gene associations was higher in monoculture. Thus, monoculture ex-vivo drug perturbation studies represent a sensitive first-line screening approach to detect drug-gene associations.

\section{Image-based phenotyping provides additional insights into drug effects}

We aggregated viability and morphological features to generate compound profiles (see Materials and Methods). Using joint mono- and coculture profiles we performed a hierarchical clustering of all screened compounds (Fig. 5). The clustering recapitulated functional drug classes including BCR inhibitors, immunomodulatory agents, JAK inhibitors, chemotherapeutics, $\mathrm{BH} 3$ mimetics, and proteasome inhibitors.

We examined which compounds were similar in one culture condition but not in the other. Several drugs displayed higher similarity in monoculture. For instance, while most BCR inhibitors were strongly correlated with one another in both mono- and coculture, high correlations of sotrastaurin and dasatinib with the other BCR inhibitors were lost in coculture (Fig. 5). JAK inhibitors clustered together, with a high correlation between ruxolitinib and pyridone- 6 observed only in monoculture. Likewise, the profiles of $\mathrm{BH} 3$ mimetics, venetoclax and UMI-77, were more similar in monoculture. Since many compounds display higher within-class heterogeneity in coculture, we hypothesize that stromal effects vary among the drugs assigned to the same functional class.

To determine relative importance of microscopy for compound profiling, we generated the clustering based on image features alone and compared it with the clustering based on viability (Supplementary Fig. S7). This revealed that the BCR inhibitor class could be recapitulated without image features. By contrast, the clustering of proteasome inhibitors or that of $\mathrm{BH} 3$ mimetics was mainly driven by morphological features (Supplementary Fig. S7). This suggests that morphological profiling is important for inferring drug mode of action of certain compound classes. 


\section{Comparison of mono- and coculture for microscopy-based screening}

Our study provides a comprehensive assessment of the stroma coculture model for compound screening in hematological cancers. We summarize the advantages and shortcomings of coculture with regard to image-based screening in Table 1.

\section{Discussion}

The bone marrow microenvironment is presumed to be one of the principal factors contributing to emergence of minimal residual disease and acquired drug resistance (Meads et al, 2008). To understand the role of the bone marrow stromal cells for drug resistance we developed a workflow suitable for high throughput screening of primary tumors cultured with bone marrow stromal cells ex vivo. We demonstrate that high-throughput screening can be reproducibly performed in complex coculture models, which can facilitate clinically relevant discoveries.

Our workflow revealed that up to $50 \%$ of compounds show partially reduced activity in the presence of bone marrow stroma, while the activity of the remaining investigated compounds was unchanged. Stroma-mediated protection from drug-induced apoptosis affected major therapeutic drug classes such as chemotherapeutics and BCR inhibitors. These effects were observed in lymphoid and myeloid malignancies, suggesting a disease-independent mechanism causing reduced drug efficacy in stromal cocultures. Despite the reduced efficacy of a substantial fraction of drugs in coculture with stromal cells, mono- and coculture drug response profiles were correlated for the majority of compounds. This observation suggests that monoculture assays might be an appropriate first-line drug screening approach for precision oncology.

However, our analysis also suggests that it is important to validate discoveries made in a monoculture system in the context of different dimensions of the cancer microenvironment. Carfilzomib and bortezomib for instance, two proteasome inhibitors, showed high efficacy in monocultures of CLL cells but almost no efficacy in cocultures of CLL and stromal cells. This parallels the observation that proteasome inhibitors did not show clinical efficacy in CLL (Faderl et al. 2006) which might be in part attributed to the effects mediated by the stroma.

Only few drugs were more active in coculture than in monoculture. JAK inhibitors reduced stroma-mediated protection in lymphoid and myeloid disease entities. The JAK-STAT pathway has been suggested as a key mediator of stromal protection (Quintarelli et al, 2014; Weisberg et al, 2012; Karjalainen et al, 2017; Severin et al, 2019). Our coculture screen confirmed the importance of the JAK-STAT signalling pathway for the crosstalk between leukemia and stromal cells. Although JAK inhibitors alone have low inhibitory activity, they could be used in combination with other clinically established drugs to reduce drug resistance in the bone marrow. Currently, JAK inhibitor combinations are being evaluated in clinical trials (Oppermann et al. 2016; Spaner et al. 2016; Spaner et al. 2019).

High-throughput ex-vivo drug assays combined with molecular profiles of the tumor cells have demonstrated great potential to become a key instrument for dissecting genotypephenotype relationships underlying drug response variation in cancer. Our data recapitulates 
clinically established genotype-drug response associations which suggests that clinically relevant biology can be read out in short-term drug response assay ex vivo. The majority of drug-gene associations were consistent between mono- and coculture, but the effect sizes of these associations in coculture were reduced. This finding further supports the notion that monoculture drug assays may serve as a first-line discovery tool for drug-gene associations due to its lower complexity and higher sensitivity.

A limitation of our stroma coculture model is the simplifying assumption that the mere presence of bone marrow stromal cells is sufficient to reproduce the bone marrow tumor microenvironment ex vivo. The bone marrow niche, however, represents a complex cellular system which contains many different cell types which may interact with blood cancer cells and may affect in vivo drug response. More complex coculture- and organoid systems (Gava et al. 2021; Bleijs et al. 2019; Ham et al. 2019) could address some of these limitations but our work suggests that simple coculture- or even monoculture models may produce informative phenotypes for personalized medicine applications.

\section{Materials and Methods}

\section{Cell culture}

HS-5 cells were maintained in DMEM (Thermo Fisher Scientific) supplemented with $10 \%$ fetal bovine serum (FBS; Thermo Fisher Scientific), $1 \%$ penicillin/streptomycin (Thermo Fisher Scientific) and $1 \%$ glutamine (Thermo Fisher Scientific) in a humidified atmosphere at $37^{\circ} \mathrm{C}$ and $10 \% \mathrm{CO}_{2}$.

\section{Patient samples}

Written consent was obtained from patients according to the declaration of Helsinki. Peripheral blood mononuclear cells (PBMCs) were isolated from blood using Ficoll density gradient centrifugation. Cells were viably frozen in RPMI (Thermo Fisher Scientific) containing $45 \%$ FBS (Thermo Fisher Scientific) and $10 \%$ DMSO (SERVA Electrophoresis $\mathrm{GmbH}$ ) and kept on liquid nitrogen until use. Cells were thawed freshly before the experiment and rolled in serum containing medium for 3 hours on a roll mixer at room temperature to allow cells to recover. To deplete dead cells, which form clumps during this procedure, the suspension was filtered through a $40 \mu \mathrm{m}$ cell strainer (Sarstedt). Cell viability and counts were analysed using Trypan Blue (Thermo Fisher Scientific). Percentages of alive cells always exceeded $90 \%$ at culture start or freezing of pellets.

\section{IGHV status analysis}

For the analysis of IGHV status RNA was isolated from $1 \times 10^{7}$ PBMCs and CDNA was synthesized via reverse transcription. Subsequent PCR reactions and analyses were based on the protocol published by Szanaski and Bahler (2010) (Szankasi \& Bahler, 2010a) with minor modifications. The AmpliTaq Gold DNA polymerase (Thermo Fisher Scientific) was used for PCR reactions. Amplification of VH1-, VH3- and VH4- segments was done in single reactions whereas amplification for $\mathrm{VH} 2, \mathrm{VH} 3-21, \mathrm{VH} 5$ and $\mathrm{VH} 6$-segments was done in a 
bioRxiv preprint doi: https://doi.org/10.1101/2022.02.18.481065; this version posted February 20, 2022. The copyright holder for this preprint (which was not certified by peer review) is the author/funder, who has granted bioRxiv a license to display the preprint in perpetuity. It is made available under aCC-BY-NC-ND 4.0 International license.

multiplex fashion as previously described (Primers for the individual PCRs: PCR1: VH1, JH, JH-1; PCR2: VH3, JH, JH-1; PCR3: VH4, JH, JH-1; PCR4: VH2, VH3-21, VH5, VH6, JH, JH1 (Szankasi \& Bahler, 2010b)). The following PCR program was used: initial denaturation $\left(94^{\circ} \mathrm{C}, 2 \mathrm{~min}\right), 40$ cycles of denaturation, annealing and elongation $\left(94^{\circ} \mathrm{C}, 20 \mathrm{sec} ; 52^{\circ} \mathrm{C}\right.$, $10 \mathrm{sec} ; 72^{\circ} \mathrm{C}, 30 \mathrm{sec}$ ) and final elongation $\left(72^{\circ} \mathrm{C}, 2 \mathrm{~min}\right)$. Sanger Sequencing (GATC Biotech) was performed on the PCR products using the appropriate forward and the $\mathrm{JH}-1$ reverse primer. In the multiplex PCR reaction both $\mathrm{JH}$-rev and $\mathrm{JH}-1$ rev were used for sequencing. Forward and reverse sequencing results were aligned. The IMGT/V-QuestDatabase was used for finding the closest matching germline $\mathrm{VH}$-sequence and identifying the mutation status, i.e. the percentage of sequence identity, of the $\mathrm{VH}$-segment determined.

\section{Panel sequencing of CLL samples}

We performed an analysis of gene mutations of the CLL candidate genes NOTCH1, SF3B1, ATM, TP53, RPS15, BIRC3, MYD88, FBXW7, POT1, XPO1, NFKBIE, EGR2 and BRAF. A customized Illumina ${ }^{\mathrm{TM}}$ TruSeq Custom Amplicon (TSCA) panel with two independent primer sets for a redundant coverage of genes was designed. The selection of targets comprised the 11 most frequently mutated genes in CLL identified via unbiased whole exome sequencing of $528 \mathrm{CLL}$ patients (Landau et al, 2015). For the following genes the full gene was covered: ATM, BIRC3, EGR2, FBXW7, MYD88, NFKBIE, POT1 and TP53. For the following genes the most commonly affected exons were covered: BRAF (exons 11-18), NOTCH1 (exon 34 +3'UTR), RPS15 (exons 3-4), SF3B1 (exons 14-16) and XPO1 (exons 14-17). Library preparation was performed using TruSeq Custom Amplicon Assay Kit v1.5 including extension and ligation steps between custom probes. Samples were indexed, pooled and loaded on an Illumina MiSeq flow cell in 32 sample batches.

Analysis was performed using BWA, Samtools (alignment; (Li, 2011)), and Varscan (variant calling and annotation; (Koboldt et al, 2012)). Current databases (COSMIC (Tate et al, 2019), 1000G (Voight et al, 2015), dbSNP145 (Kitts et al, 2014), ClinVar (Landrum et al, 2018)) were considered to evaluate variants above a threshold of $5 \%$ mean variant allele fraction (VAF) as pathogenic/non pathogenic. Only mutations occurring at an allele frequency of more than $20 \%$ and in at least three patients were considered.

\section{DNA copy number variants}

Assessment of DNA copy numbers was done using Illumina CytoSNP-12 and HumanOmni2.5-8 microarrays and read out using an iScan array scanner. Fluorescence in situ hybridization (FISH) analysis was performed for del11q22.3, del17p13, del13q14, trisomy 12, gain8q24 and gain14q32. Only alterations present in at least three patients and absent in at least three patients were considered.

\section{Coculture drug screen}

\section{Preparation of drug plates}

For the screen, 50 drugs were probed at 3 different concentrations (Supplementary Table 1). Drug concentrations ranged from subnanomolar to low micromolar and were chosen based 
bioRxiv preprint doi: https://doi.org/10.1101/2022.02.18.481065; this version posted February 20, 2022. The copyright holder for this preprint (which was not certified by peer review) is the author/funder, who has granted bioRxiv a license to display the preprint in perpetuity. It is made available under aCC-BY-NC-ND 4.0 International license.

on previous experience with the drugs (Dietrich et al, 2018). Increase of the concentration was 15-fold per step to cover a broad spectrum of concentrations. Drugs were diluted according to the manufacturer's instructions. Further dilution was carried out in DMSO (SERVA Electrophoresis $\mathrm{GmbH}$ ) and master plates containing $4 \mu \mathrm{L}$ of diluted drugs were frozen at $-20^{\circ} \mathrm{C}$ for direct use on the screening days.

\section{Compound screening of mono- and cocultures}

On the screening day, HS-5 stromal cells were detached and seeded at a density of $1 \times 10^{4}$ cells/well in $20 \mu \mathrm{l}$ into the columns with even numbers of CellCarrier-384 Ultra Microplates (Perkin Elmer). The high cell count enables even distribution of cells across the well. The columns with uneven numbers were filled with the same amount of medium. The cells were left at $37^{\circ} \mathrm{C}$ for 3-4 hours to permit attachment.

In the meantime, leukemia cells were thawed and allowed to recover, as described above. On each screening day either 5 or 10 patient samples were screened. Drug master plates were thawed and the content diluted in $96 \mu \mathrm{l}$ serum free medium per well. $2.5 \mu \mathrm{l}$ of drugs were transferred to the attached stroma cells, before adding $17.5 \mu \mathrm{L}$ containing $2 \times 10^{4}$ patient cells per well. The whole screen was carried out in DMEM (Thermo Fisher Scientific) supplemented with $10 \%$ human serum (male AB, H6914-100ml Batch SLBT2873, SigmaAldrich), $1 \%$ penicillin/streptomycin (Thermo Fisher Scientific) and $1 \%$ glutamine (Thermo Fisher Scientific) at a final volume of $40 \mu \mathrm{L}$ in the culture plates. Cells were incubated at $37^{\circ} \mathrm{C}$ in a humidified atmosphere and $10 \% \mathrm{CO}_{2}$ for 3 days.

\section{Spinning disk confocal microscopy}

High-throughput screening was conducted using Opera Phenix High Content Screening System (Perkin Elmer). CLL screening plates were stained with $4 \mathrm{~g} / \mathrm{ml}$ Hoechst 33342 (Invitrogen) and $1 \mathrm{l} / \mathrm{ml}$ lysosomal dye NIR (Abcam). Plates of non-CLL entities were additionally stained with calcein AM $(1 \mu \mathrm{M}$, Invitrogen). Three positions per well with a stack of ten images at a distance of $1.2 \mu \mathrm{m}$ were acquired with a $40 \mathrm{x}$ water objective in confocal mode.

\section{Validation of screening results in primary MSC cocultures}

Primary mesenchymal stromal cells (MSCs) derived from three different healthy donors were used. 1000 cells/well were seeded in 96-well glass bottom plates (zell-kontakt $\mathrm{GmbH}$ ) in MSCGM $^{\mathrm{TM}}$ Mesenchymal Stem Cell Growth Bulletkit Medium (Lonza). The plates were cultured in a humidified atmosphere at $37^{\circ} \mathrm{C}$ and $5 \% \mathrm{CO}_{2}$ for 2 days to allow MSCs to adhere and recover. CLL cells were thawed, allowed to recover in medium for 3 hours and filtered through a $40 \mu \mathrm{m}$ cell strainer (Sarstedt) to get rid of dead cells. The medium was removed from MSCs and $2 \times 10^{5} \mathrm{CLL}$ cells/well added to the stroma cells in Bulletkit medium (Lonza). Apart from cocultures, monocultures of CLL cells were established. Cultures were treated with $1.5 \mu \mathrm{M}$ JQ1, $0.6 \mu \mathrm{M}$ Fludarabine, $22.5 \mu \mathrm{M}$ tofacitinib, $9 \mu \mathrm{M}$ ruxolitinib or solvent control (DMSO; SERVA Electrophoresis $\mathrm{GmbH}$ ) and incubated in a humidified atmosphere at $37^{\circ} \mathrm{C}$ and $5 \% \mathrm{CO}_{2}$ for 3 days. Each condition was assessed in technical duplicates. The cultures were stained with Hoechst 33342 ( $4 \mathrm{~g} / \mathrm{ml}$, Invitrogen), calcein AM (1 $\mu \mathrm{M}$, Invitrogen), PI (5 g/ml, Sigma-Aldrich) and lysosomal dye NIR (1 l/ml, Abcam) and the whole wells were imaged on an Opera Phenix microscope (Perkin Elmer) with a 10x objective in confocal 
bioRxiv preprint doi: https://doi.org/10.1101/2022.02.18.481065; this version posted February 20, 2022. The copyright holder for this preprint (which was not certified by peer review) is the author/funder, who has granted bioRxiv a license to display the preprint in perpetuity. It is made available under aCC-BY-NC-ND 4.0 International license.

mode. Using the image analysis software Harmony (Perkin Elmer), CLL cells were segmented based on Hoechst signal and calcein and $\mathrm{PI}$ intensities were measured. All further analysis steps were conducted in R (R Core Team, 2018). Cells with a calcein intensity above a certain threshold and with PI intensities below a certain threshold were classified as alive. To avoid a possible influence of phagocytosis on relative percentages of alive cells (Herbst et al, 2021), absolute counts of alive CLL cells were used for all further analyses. These viabilities were normalised by division through viabilities in DMSO controls.

\section{Western blot analysis}

To assess the impact of stroma coculture on STAT3 phosphorylation in CLL cells, DMEM medium supplemented with $10 \%$ human serum (male AB, H6914-100ml Batch SLBT2873, Sigma-Aldrich), $1 \%$ penicillin/streptomycin (Thermo Fisher Scientific) and $1 \%$ glutamine (Thermo Fisher Scientific) or $5 \times 10^{6}$ HS-5 cells were pre-plated into $10 \mathrm{~cm}$ dishes. After 3 hours CLL cells were added at $1.5 \times 10^{7}$ cells/dish to establish mono- and cocultures. DMSO $(0.22 \%$; SERVA Electrophoresis $\mathrm{GmbH})$, ruxolitinib $(10 \mu \mathrm{M})$ or tofacitinib $(22 \mu \mathrm{M})$ were added. After incubation for 48 hours CLL cells were carefully harvested. Cells were counted using Trypan Blue (Thermo Fisher Scientific) and contamination with HS-5 cells was excluded by visual inspection.

To assess the impact of soluble factors produced by stroma, HS-5 cells or primary MSCs were cultured in DMEM medium supplemented with $10 \%$ FBS (Thermo Fisher Scientific), $1 \%$ penicillin/streptomycin (Thermo Fisher Scientific) and $1 \%$ glutamine (Thermo Fisher Scientific) or Bulletkit medium (Lonza) respectively. Conditioned medium was harvested after 3 days of culture. After the removal of cellular debris by centrifugation at $1000 \mathrm{~g}$, aliquots of conditioned medium were frozen. $7.5 \times 10^{6} \mathrm{CLL}$ patient cells in DMEM medium supplemented with $10 \%$ FBS (Thermo Fisher Scientific), 1\% penicillin/streptomycin (Thermo Fisher Scientific), $1 \%$ glutamine (Thermo Fisher Scientific) and $25 \%$ conditioned medium were seeded into $10 \mathrm{~cm}$ dishes. Cells were harvested after culturing for 48 hours.

Samples for Western Blot were prepared by washing once with ice-cold PBS (Thermo Fisher Scientific) and lysed in $100 \mu$ RIPA buffer (Sigma-Aldrich) containing PhosSTOP (SigmaAldrich) and cOmplete, Mini Protease Inhibitor Cocktail (Sigma-Aldrich). After incubation on ice for $30 \mathrm{~min}$ the samples were centrifuged at $15,000 \mathrm{~g}$ for $20 \mathrm{~min}$ at $4{ }^{\circ} \mathrm{C}$. The supernatant was aliquoted and frozen at $-80^{\circ} \mathrm{C}$ until use. Samples were run on $10 \%$ acrylamide gels (SERVA Electrophoresis $\mathrm{GmbH}$ ) at $45 \mathrm{~mA}$. As marker, the dual color Precision Plus (BioRad Laboratories) ladder was used. Transfer to PVDF membranes (Thermo Fisher Scientific) was performed at $400 \mathrm{~mA}$. Primary antibodies were incubated overnight. Primary and secondary antibodies are listed in Supplementary Table 5.

\section{Processing of images (CLL)}

Images of CLL samples were processed using the image analysis software Harmony (Perkin Elmer). Stacks were processed by using maximum intensity projection. CLL nuclei were identified by segmentation of the Hoechst channel and separated from stroma cell nuclei based on the area of the nucleus. Results were exported and further analysis was conducted in the statistical programming language $R$ ( $R$ Core Team, 2018). To assess whether a cell was alive or dead, the area of the nucleus of each individual cell was determined. When CLL 
cells die the nucleus condenses and, therefore, gets smaller and brighter. By plotting a histogram of nuclear area across all plates and patients we determined that a threshold of $23.8 \mu^{2}$ can distinguish the two populations of alive and dead cells most accurately. This method had previously been validated by concurrent staining with the viability dye calcein AM (Supplementary Fig. S1 D). Using this threshold cells were classified into alive and dead and the percentage of alive cells was calculated for each well.

\section{Image analysis in non-CLL entities}

Maximum intensity projection and gamma correction (gamma $=0.3$ ) was applied to all images. All 3 color channels (lysosomal dye, calcein and Hoechst) were combined to generate RGB overlays. Each image ( $2160 \times 2160$, omitting the color channel axis) was cut into 9 blocks of size $720 \times 720$ to speed up training and prediction.

Faster R-CNN object detection model (Ren et al, 2017) with Inception v2 (Szegedy et al, 2015) backbone architecture was used to detect patient-derived leukemia and lymphoma cells. The two defined classes were viable and apoptotic leukemia cells. The object detection model implemented in TensorFlow 1.14 was trained for 21,000 epochs on coculture images from $5 \mathrm{AML}$ samples. 5 control and 5 drug-treated well images were randomly selected from each of the five AML plates, resulting in $5 * 10 * 9=450$ images that were split into train / test sets with $80 \% / 20 \%$ ratio. The average precision (AP) on the test set was 0.99 and 0.93 for viable and apoptotic leukemia cells, respectively (Supplementary Fig. S1 E). The area under the ROC curve (AUCROC) was 0.98 for both viable and apoptotic leukemia cells (Supplementary Fig. S1 F).

\section{Morphological profiling, quality control and normalization}

After image segmentation, morphological properties describing size, intensity, shape and texture were computed for each cell. Morphological profiling of patient-derived leukemia cells produced 1401 image features in non-CLL entities and 934 features in CLL. In all downstream analyses, we used only a subset of features with high replicate correlation $(r>$ 0.5). After filtering based on replicate correlation, we obtained 173 morphological features in non-CLL entities and 194 features in CLL.

All morphological properties were normalized to control values. Mean and standard deviation of each image feature were estimated using untreated wells in mono- and coculture, respectively. All morphological features were centered and scaled:

$x_{\text {norm }}=\frac{x-\mu_{M}}{\sigma_{M}}$ monoculture

$x_{\text {norm }}=\frac{x-\mu_{C}}{\sigma_{C}}$ coculture

\section{Quantification and visualization of morphological changes}

Median values were estimated for each morphological feature in every probed condition. The difference of medians $\left(m_{C}-m_{M}\right)$ in coculture and monoculture was computed to quantify stroma-induced morphological changes in each sample. 
Coculture and monoculture cell populations of each sample were jointly embedded using tSNE (Van Der Maaten \& Hinton, 2008). The t-SNE algorithm was applied to the first 20 principal components (PCs) of single-cell morphological feature data.

\section{Spontaneous apoptosis, drug sensitivity and normalization}

Only viable and apoptotic leukemia cell counts were used for drug sensitivity analysis. Viability was computed as the ratio of viable cell count to the total cell count. For each sample, baseline viabilities $\left(b_{M}, b_{C}\right)$ were defined as mean viabilities of untreated wells of the respective culture condition. Untreated wells on the plate edge were excluded, resulting in 11 and 13 wells used for estimation of baseline viability in mono- and coculture, respectively. Spontaneous apoptosis rate was evaluated as the complement of baseline viability: $S A=$ $1-b$.

Drug sensitivities were computed by normalizing viabilities to baseline values of the respective culture condition:

$v_{\text {norm }}=\frac{v}{b_{M}}$ monoculture

$v_{\text {norm }}=\frac{v}{b_{C}}$ coculture

\section{Compound efficacy changes in coculture}

For each drug, we selected the concentration with maximum variance in terms of normalized viability and applied a paired $t$-test with the null hypothesis $H_{0}$ assuming equal drug sensitivities in mono- and coculture. Drug concentrations toxic to stroma cells were excluded prior to statistical testing, but were retained for dose-response fitting.

To compute the effect size, median dose-response curves were computed for mono- and coculture. The effect size was calculated as the percentage change in area under the doseresponse curves in coculture:

$$
\text { Effect size }=\frac{A U C_{C}-A U C_{M}}{A U C_{M}} \cdot 100 \%
$$

In CLL coculture, compounds with changed efficacy had adjusted p-values $<0.01$ and leffect size| $>5 \%$. In AML coculture, the same thresholds were used, except for those compounds that change efficacy in CLL coculture, for which only the effect size cutoff of $5 \%$ was used.

\section{Drug-gene associations}

For 80 CLL samples, genetic features such as IGHV mutation status, somatic mutations (TP53, ATM, etc) and chromosomal aberrations (del11q, trisomy 12, etc) were available. To test whether mean drug sensitivities of wildtype and mutated cases were equal, we applied a $t$-test on normalized viabilities for each drug stratified by mutational status. The statistical tests were performed separately in mono- and coculture. 


\section{Image feature selection for compound profiling}

A non-redundant morphological feature set was constructed using the method described in (Fischer et al. 2015). Briefly, an initial set of 2-3 features was provided. At each iteration, all other features were regressed against the set of selected features and the feature with the highest replicate correlation between regression residuals was added. The iterative procedure continued until the number of features with positive correlations between residuals was exceeding the number of those with negative correlations. The selected features used for compound profiling are provided in Supplementary Tables 7-8.

\section{Compound profiling and hierarchical clustering}

Selected morphological features were used to generate compound profiles by aggregating the observed features across all screened samples in both culture conditions. These imagebased profiles were used for hierarchical clustering of probed compounds. Drug-drug correlations of image-based profiles were used to measure drug similarities independently in mono- and coculture.

\section{Data availability}

Drug concentration data: Supplementary Table 1

Sample genetic information: Supplementary Tables 2 and 3

Drug response data: TSV file

Imaging data: will be made available via Imaging Data Resource (IDR)

\section{Software availability}

Image analysis and morphological profiling were conducted in Python and the code is available on Github: https://github.com/vladchimescu/microscopy-notebooks. git. Statistical analysis of processed viability and morphological feature data was performed in $\mathrm{R}$ and the code is available on Github: https://github.com/vladchimescu/coculture.git.

\section{Acknowledgements}

The authors thank all patients for the donation of cells. The authors gratefully acknowledge the data storage service SDS@hd supported by the Ministry of Science, Research and the Arts Baden-Württemberg (MWK) and the German Research Foundation (DFG) through grant INST 35/1314-1 FUGG. SD was supported by the Else Kroener Physician Scientist Professorship, Heidelberg Research Centre for Molecular Medicine (HRCMM), an e:med BMBF junior group grant, and Deutsche Forschungsgemeinschaft (DFG). NL was supported by a Heidelberg School of Oncology (HSO2) fellowship from the National Center for Tumor Diseases (NCT) Heidelberg. The authors thank Benedikt Brors, Simon Anders, Beate Neumann, Sandrine Sander, Martina Seiffert, Christof von Kalle and Bernd Fischer for helpful discussions. The authors thank Angela Lenze, Tatjana Walter, Ximing Ding and Rainer Saffrich for technical support. 


\section{Author contributions}

SAH conducted the screen. SAH, PMB, TR, CK and MK performed validation experiments. VK and SAH performed computational analyses. ECS performed data curation and $\mathrm{JL}$ processed NGS data. NL collected patient data. CL, PD, CMT and TZ provided guidance and feedback. SAH, VK, SD wrote the manuscript. SAH and VK contributed equally to this work. SD and $\mathrm{WH}$ jointly supervised this work.

\section{Conflict of interest}

The authors declare that they have no conflict of interest.

\section{References}

Amrein PC, Attar EC, Takvorian T, Hochberg EP, Ballen KK, Leahy KM, Fisher DC, Lacasce AS, Jacobsen ED, Armand P, et al (2011) Phase II study of dasatinib in relapsed or refractory chronic lymphocytic leukemia. Clin Cancer Res 17: 2977-2986

Barretina J, Caponigro G, Stransky N, Venkatesan K, Margolin AA, Kim S, Wilson CJ, Lehár J, Kryukov GV, Sonkin D, et al (2012) The Cancer Cell Line Encyclopedia enables predictive modelling of anticancer drug sensitivity. Nature 483: 603-607

Bendall LJ, Daniel A, Kortlepel K \& Gottlieb DJ (1994) Bone marrow adherent layers inhibit apoptosis of acute myeloid leukemia cells. Exp Hematol 22: 1252-1260

Bray M-A, Singh S, Han H, Davis CT, Borgeson B, Hartland C, Kost-Alimova M, Gustafsdottir SM, Gibson CC \& Carpenter AE (2016) Cell Painting, a high-content image-based assay for morphological profiling using multiplexed fluorescent dyes. Nat Protoc 11: 1757-1774

Bruch P-M, Giles HAR, Kolb C, Herbst SA, Becirovic T, Roider T, Lu J, Scheinost S, Wagner L, Huellein J, et al (2021) Mapping drug-microenvironment-genetic interplay in CLL reveals trisomy 12 as a modulator of microenvironmental signals. bioRxiv

Burger JA \& O'Brien S (2018) Evolution of CLL treatment - from chemoimmunotherapy to targeted and individualized therapy. Nat Rev Clin Oncol 15: 510-527

Collins RJ, Verschuer LA, Harmon BV, Prentice RL, Pope JH \& Kerr JF (1989) Spontaneous programmed death (apoptosis) of B-chronic lymphocytic leukaemia cells following their culture in vitro. Br J Haematol 71: 343-350

Coscia M, Pantaleoni F, Riganti C, Vitale C, Rigoni M, Peola S, Castella B, Foglietta M, Griggio V, Drandi D, et al (2011) IGHV unmutated CLL B cells are more prone to spontaneous apoptosis and subject to environmental prosurvival signals than mutated CLL B cells. Leukemia 25: 828-837

Dietrich S, Oleś M, Lu J, Sellner L, Anders S, Velten B, Wu B, Hüllein J, da Silva Liberio M, Walther T, et al (2018) Drug-perturbation-based stratification of blood cancer. J Clin Invest 128: 427-445

Dubois N, Crompot E, Meuleman N, Bron D, Lagneaux L \& Stamatopoulos B (2020) 
bioRxiv preprint doi: https://doi.org/10.1101/2022.02.18.481065; this version posted February 20, 2022. The copyright holder for this preprint (which was not certified by peer review) is the author/funder, who has granted bioRxiv a license to display the preprint in perpetuity. It is made available under aCC-BY-NC-ND 4.0 International license.

Importance of Crosstalk Between Chronic Lymphocytic Leukemia Cells and the Stromal Microenvironment: Direct Contact, Soluble Factors, and Extracellular Vesicles. Front Oncol 10: 1422

Garnett MJ, Edelman EJ, Heidorn SJ, Greenman CD, Dastur A, Lau KW, Greninger P, Thompson IR, Luo X, Soares J, et al (2012) Systematic identification of genomic markers of drug sensitivity in cancer cells. Nature 483: 570-575

Guo A, Lu P, Galanina N, Nabhan C, Smith SM, Coleman M \& Wang YL (2016) Heightened BTK-dependent cell proliferation in unmutated chronic lymphocytic leukemia confers increased sensitivity to ibrutinib. Oncotarget 7: 4598-4610

Herbst SA, Stolarczyk M, Becirovic T, Czernilofsky F, Liu Y, Kolb C, Knoll M, Herling M, Müller-Tidow C \& Dietrich S (2021) Phagocytosis by stroma confounds coculture studies. iScience 24: 103062

lorio F, Knijnenburg TA, Vis DJ, Bignell GR, Menden MP, Schubert M, Aben N, Gonçalves E, Barthorpe S, Lightfoot H, et al (2016) A Landscape of Pharmacogenomic Interactions in Cancer. Cell 166: 740-754

Karjalainen R, Pemovska T, Popa M, Liu M, Javarappa KK, Majumder MM, Yadav B, Tamborero D, Tang J, Bychkov D, et al (2017) JAK1/2 and BCL2 inhibitors synergize to counteract bone marrow stromal cell-induced protection of AML. Blood 130: 789-802

Kay NE, Shanafelt TD, Strege AK, Lee YK, Bone ND \& Raza A (2007) Bone biopsy derived marrow stromal elements rescue chronic lymphocytic leukemia B-cells from spontaneous and drug induced cell death and facilitates an 'angiogenic switch'. Leuk Res 31: 899-906

Kitts A, Phan L, Ward M \& Holmes JB (2014) The Database of Short Genetic Variation (dbSNP). In The NCBI Handbook [Internet]. 2nd edition National Center for Biotechnology Information (US)

Koboldt DC, Zhang Q, Larson DE, Shen D, McLellan MD, Lin L, Miller CA, Mardis ER, Ding L \& Wilson RK (2012) VarScan 2: somatic mutation and copy number alteration discovery in cancer by exome sequencing. Genome Res 22: 568-576

Konopleva M, Konoplev S, Hu W, Zaritskey AY, Afanasiev BV \& Andreeff M (2002) Stromal cells prevent apoptosis of AML cells by up-regulation of anti-apoptotic proteins. Leukemia 16: 1713-1724

Kurtova AV, Balakrishnan K, Chen R, Ding W, Schnabl S, Quiroga MP, Sivina M, Wierda WG, Estrov Z, Keating MJ, et al (2009) Diverse marrow stromal cells protect CLL cells from spontaneous and drug-induced apoptosis: development of a reliable and reproducible system to assess stromal cell adhesion-mediated drug resistance. Blood 114: 4441-4450

Lagneaux L, Delforge A, Bron D, De Bruyn C \& Stryckmans P (1998) Chronic lymphocytic leukemic $B$ cells but not normal $B$ cells are rescued from apoptosis by contact with normal bone marrow stromal cells. Blood 91: 2387-2396

Landau DA, Tausch E, Taylor-Weiner AN, Stewart C, Reiter JG, Bahlo J, Kluth S, Bozic I, Lawrence M, Böttcher S, et al (2015) Mutations driving CLL and their evolution in progression and relapse. Nature 526: 525-530

Landrum MJ, Lee JM, Benson M, Brown GR, Chao C, Chitipiralla S, Gu B, Hart J, Hoffman 
bioRxiv preprint doi: https://doi org/10.1101/2022.02 18.481065; this version posted February 20,2022 . The copyright holder for this preprint (which was not certified by peer review) is the author/funder, who has granted bioRxiv a license to display the preprint in perpetuity. It is made available under aCC-BY-NC-ND 4.0 International license.

D, Jang W, et al (2018) ClinVar: improving access to variant interpretations and supporting evidence. Nucleic Acids Res 46: D1062-D1067

Liebers N, Bruch P-M, Gambietz A, Giles H, Lu J, Knoll M, Kolb C, Dreger P, Mueller-Tidow C, Huber W, et al (2019) Ex-vivo drug response profiling for tailoring treatment in hematologic malignancies: The prospective non-interventional SMART-trial. Blood 134: 376-376

Li H (2011) A statistical framework for SNP calling, mutation discovery, association mapping and population genetical parameter estimation from sequencing data. Bioinformatics 27: 2987-2993

Loo L-H, Wu LF \& Altschuler SJ (2007) Image-based multivariate profiling of drug responses from single cells. Nat Methods 4: 445-453

Lu J, Cannizzaro E, Meier-Abt F, Scheinost S, Bruch P-M, Giles HA, Lütge A, Hüllein J, Wagner L, Giacopelli B, et al (2021) Multi-omics reveals clinically relevant proliferative drive associated with mTOR-MYC-OXPHOS activity in chronic lymphocytic leukemia. Nat Cancer 2: 853-864

Lukas M, Velten B, Sellner L, Tomska K, Hüellein J, Walther T, Wagner L, Muley C, Wu B, Oleś $M$, et al (2020) Survey of ex vivo drug combination effects in chronic lymphocytic leukemia reveals synergistic drug effects and genetic dependencies. Leukemia 34: 2934-2950

MacDonald ML, Lamerdin J, Owens S, Keon BH, Bilter GK, Shang Z, Huang Z, Yu H, Dias J, Minami T, et al (2006) Identifying off-target effects and hidden phenotypes of drugs in human cells. Nat Chem Biol 2: 329-337

McCaig AM, Cosimo E, Leach MT \& Michie AM (2012) Dasatinib inhibits CXCR4 signaling in chronic lymphocytic leukaemia cells and impairs migration towards CXCL12. PLoS One 7: e48929

Meads MB, Hazlehurst LA \& Dalton WS (2008) The bone marrow microenvironment as a tumor sanctuary and contributor to drug resistance. Clin Cancer Res 14: 2519-2526

Mraz M, Zent CS, Church AK, Jelinek DF, Wu X, Pospisilova S, Ansell SM, Novak AJ, Kay NE, Witzig TE, et al (2011) Bone marrow stromal cells protect lymphoma B-cells from rituximab-induced apoptosis and targeting integrin $\alpha-4-\beta-1$ (VLA-4) with natalizumab can overcome this resistance. Br J Haematol 155: 53-64

Mudry RE, Fortney JE, York T, Hall BM \& Gibson LF (2000) Stromal cells regulate survival of B-lineage leukemic cells during chemotherapy. Blood 96: 1926-1932

Oppermann S, Lam AJ, Tung S, Shi Y, McCaw L, Wang G, Ylanko J, Leber B, Andrews D \& Spaner DE (2016) Janus and PI3-kinases mediate glucocorticoid resistance in activated chronic leukemia cells. Oncotarget 7: 72608-72621

Orlova A, Neubauer HA \& Moriggl R (2019) The stromal microenvironment provides an escape route from FLT3 inhibitors through the GAS6-AXL-STAT5 axis. Haematologica 104: 1907-1909

Panayiotidis P, Jones D, Ganeshaguru K, Foroni L \& Hoffbrand AV (1996) Human bone marrow stromal cells prevent apoptosis and support the survival of chronic lymphocytic leukaemia cells in vitro. Br J Haematol 92: 97-103 
bioRxiv preprint doi: https://doi org/10.1101/2022.02.18.481065; this version posted February 20, 2022. The copyright holder for this preprint (which was not certified by peer review) is the author/funder, who has granted bioRxiv a license to display the preprint in perpetuity. It is made available under aCC-BY-NC-ND 4.0 International license.

Perlman ZE, Slack MD, Feng Y, Mitchison TJ, Wu LF \& Altschuler SJ (2004) Multidimensional drug profiling by automated microscopy. Science 306: 1194-1198

Quintarelli C, De Angelis B, Errichiello S, Caruso S, Esposito N, Colavita I, Raia M, Pagliuca S, Pugliese N, Risitano AM, et al (2014) Selective strong synergism of Ruxolitinib and second generation tyrosine kinase inhibitors to overcome bone marrow stroma related drug resistance in chronic myelogenous leukemia. Leuk Res 38: 236-242

Ren S, He K, Girshick R \& Sun J (2017) Faster R-CNN: Towards Real-Time Object Detection with Region Proposal Networks. IEEE Trans Pattern Anal Mach Intell 39: 1137-1149

Severin F, Frezzato F, Visentin A, Martini V, Trimarco V, Carraro S, Tibaldi E, Brunati AM, Piazza F, Semenzato G, et al (2019) In Chronic Lymphocytic Leukemia the JAK2/STAT3 Pathway Is Constitutively Activated and Its Inhibition Leads to CLL Cell Death Unaffected by the Protective Bone Marrow Microenvironment. Cancers 11

Sison EAR, Magoon D, Li L, Annesley CE, Rau RE, Small D \& Brown P (2014) Plerixafor as a chemosensitizing agent in pediatric acute lymphoblastic leukemia: efficacy and potential mechanisms of resistance to CXCR4 inhibition. Oncotarget 5: 8947-8958

Snijder B, Vladimer GI, Krall N, Miura K, Schmolke A-S, Kornauth C, Lopez de la Fuente O, Choi H-S, van der Kouwe E, Gültekin S, et al (2017) Image-based ex-vivo drug screening for patients with aggressive haematological malignancies: interim results from a single-arm, open-label, pilot study. Lancet Haematol 4: e595-e606

Spaner DE, Wang G, McCaw L, Li Y, Disperati P, Cussen M-A \& Shi Y (2016) Activity of the Janus kinase inhibitor ruxolitinib in chronic lymphocytic leukemia: results of a phase II trial. Haematologica 101: e192-5

Szankasi P \& Bahler DW (2010a) Clinical laboratory analysis of immunoglobulin heavy chain variable region genes for chronic lymphocytic leukemia prognosis. J Mol Diagn 12: 244249

Szankasi P \& Bahler DW (2010b) Clinical laboratory analysis of immunoglobulin heavy chain variable region genes for chronic lymphocytic leukemia prognosis. J Mol Diagn 12: 244 249

Szegedy C, Liu W, Jia Y, Sermanet P, Reed S, Anguelov D, Erhan D, Vanhoucke V \& Rabinovich A (2015) Going deeper with convolutions. In 2015 IEEE Conference on Computer Vision and Pattern Recognition (CVPR) IEEE

Tate JG, Bamford S, Jubb HC, Sondka Z, Beare DM, Bindal N, Boutselakis H, Cole CG, Creatore C, Dawson E, et al (2019) COSMIC: the Catalogue Of Somatic Mutations In Cancer. Nucleic Acids Res 47: D941-D947

Ten Hacken E \& Burger JA (2016) Microenvironment interactions and B-cell receptor signaling in Chronic Lymphocytic Leukemia: Implications for disease pathogenesis and treatment. Biochim Biophys Acta 1863: 401-413

Uy GL, Rettig MP, Motabi IH, McFarland K, Trinkaus KM, Hladnik LM, Kulkarni S, Abboud CN, Cashen AF, Stockerl-Goldstein KE, et al (2012) A phase 1/2 study of chemosensitization with the CXCR4 antagonist plerixafor in relapsed or refractory acute myeloid leukemia. Blood 119: 3917-3924

Van Der Maaten L \& Hinton G (2008) Visualizing Data using t-SNE. J Mach Learn Res 9: 
bioRxiv preprint doi: https://doi. org/10.1101/2022.02.18.481065. this version posted February 20, 2022. The copyright holder for this preprint (which was not certified by peer review) is the author/funder, who has granted bioRxiv a license to display the preprint in perpetuity. It is made available under aCC-BY-NC-ND 4.0 International license.

2579-2605

Voight BF, Trynka G, B. Howie, C. Fuchsberger, M. Stephens, J. Marchini, GR. Abecasis, Xue Y, H. Jung, T. Bleazard, J. Lee, D. Hong, YB. Simons, MC. Turchin, JK. Pritchard, G. Sella, Do R, D H Alexander J Novembre, I. Mathieson GM, H. Li RD, et al (2015) A global reference for human genetic variation. Nature 526: 68-74

Warsch W, Walz C \& SexI V (2013) JAK of all trades: JAK2-STAT5 as novel therapeutic targets in BCR-ABL1+ chronic myeloid leukemia. Blood 122: 2167-2175

Weisberg E, Liu Q, Nelson E, Kung AL, Christie AL, Bronson R, Sattler M, Sanda T, Zhao Z, Hur W, et al (2012) Using combination therapy to override stromal-mediated chemoresistance in mutant FLT3-positive AML: synergism between FLT3 inhibitors, dasatinib/multi-targeted inhibitors and JAK inhibitors. Leukemia 26: 2233-2244

Xu X, Zhang X, Liu Y, Yang L, Huang S, Lu L, Wang S, Guo Q \& Zhao L (2016) BM microenvironmental protection of CML cells from imatinib through Stat5/NF-kB signaling and reversal by Wogonin. Oncotarget 7: 24436-24454

Zhang W, Trachootham D, Liu J, Chen G, Pelicano H, Garcia-Prieto C, Lu W, Burger JA, Croce CM, Plunkett W, et al (2012) Stromal control of cystine metabolism promotes cancer cell survival in chronic lymphocytic leukaemia. Nat Cell Biol 14: 276-286

Zhang X, Tu H, Yang Y, Jiang X, Hu X, Luo Q \& Li J (2019) Bone marrow-derived mesenchymal stromal cells promote resistance to tyrosine kinase inhibitors in chronic myeloid leukemia via the IL-7/JAK1/STAT5 pathway. J Biol Chem 294: 12167-12179 
bioRxiv preprint doi: $\mathrm{https}$ //doi org/10.1101/2022.02 18.481065; this version posted February 20, 2022. The copyright holder for this preprint (which was not certified by peer review) is the author/funder, who has granted bioRxiv a license to display the preprint in perpetuity. It is made available under aCC-BY-NC-ND 4.0 International license.

A

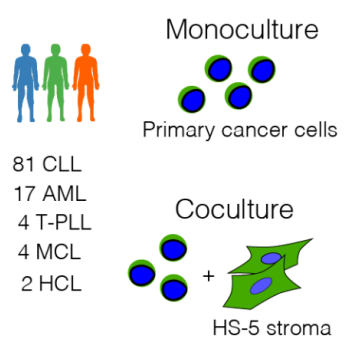

B

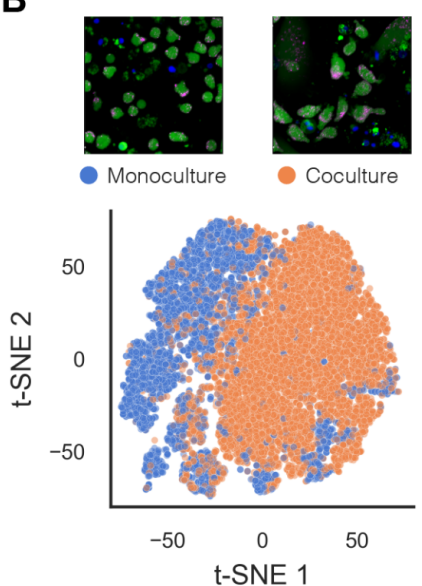

High-throughput compound screen in leukemia-stroma coculture
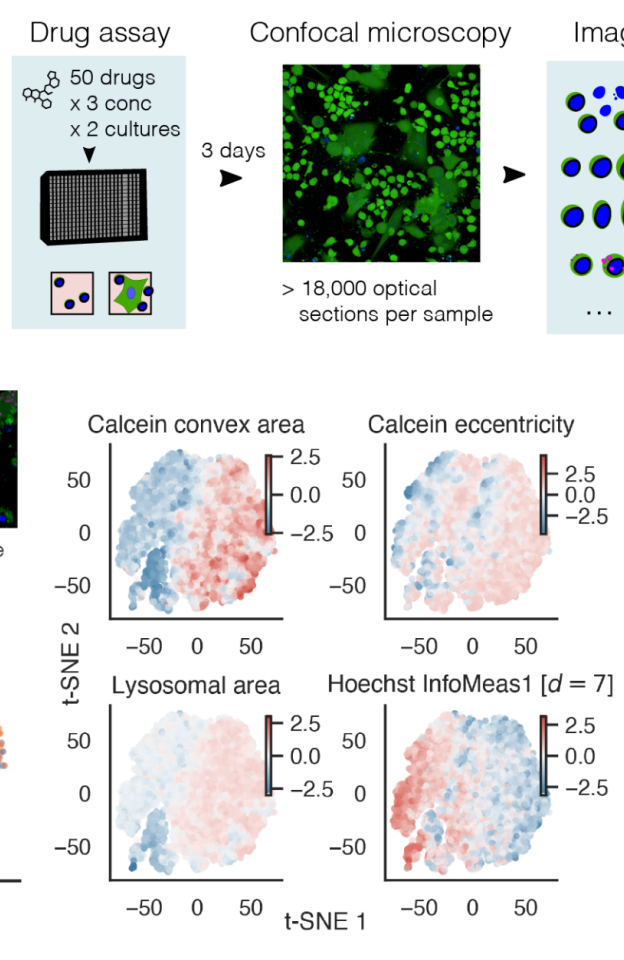

Image analysis
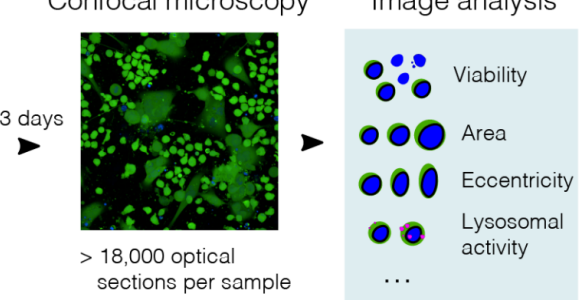

C

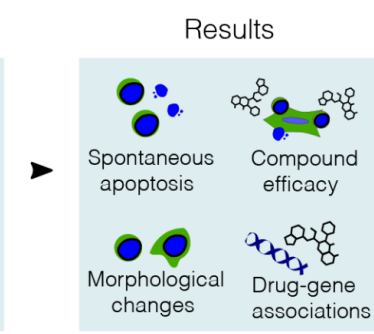

Morphological changes in coculture

Figure 1: Imaging-based coculture screen in primary leukemias and lymphomas

A) Study outline. 50 compounds were probed in 108 primary leukemia and lymphoma samples. Confocal microscopy images of leukemia cells alone (in monoculture) and in coculture with the HS-5 stromal cell line were acquired to compute viability and morphological properties. B) Joint t-SNE embedding of viable leukemia cells in mono- and coculture controls of an AML sample. Coloring by morphological features revealed that AML cells in coculture had more elongated shapes (higher eccentricity), larger cell (Calcein) and lysosomal area as well as lower local correlation between pixel intensity values in $\mathrm{x}$ - and $y$-direction (Hoechst InfoMeas1). C) Heatmap showing morphological changes in coculture controls across all screened disease entities. Grey indicates missing values. For mathematical definition of morphological properties see Supplementary Table 9. 
A

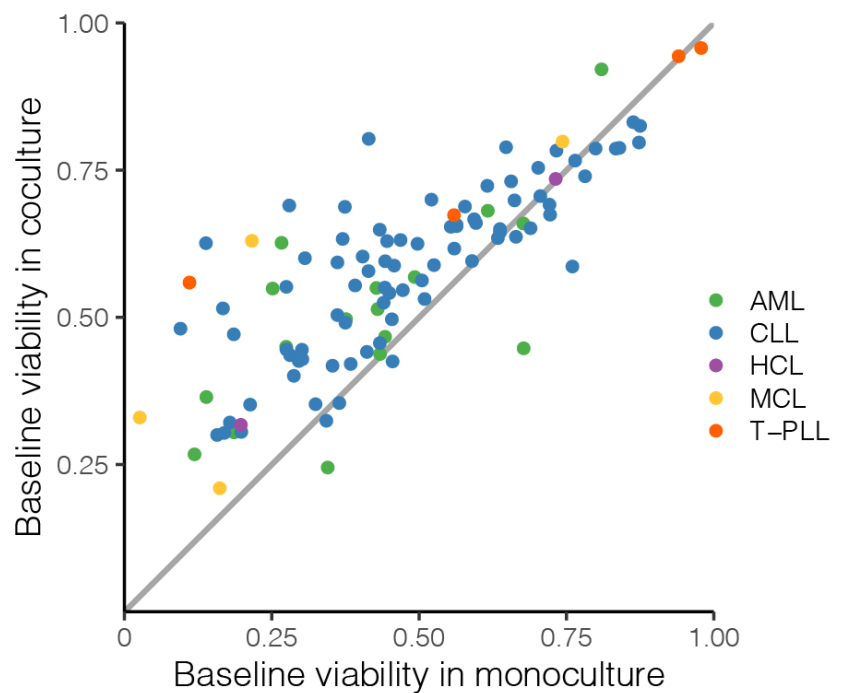

B

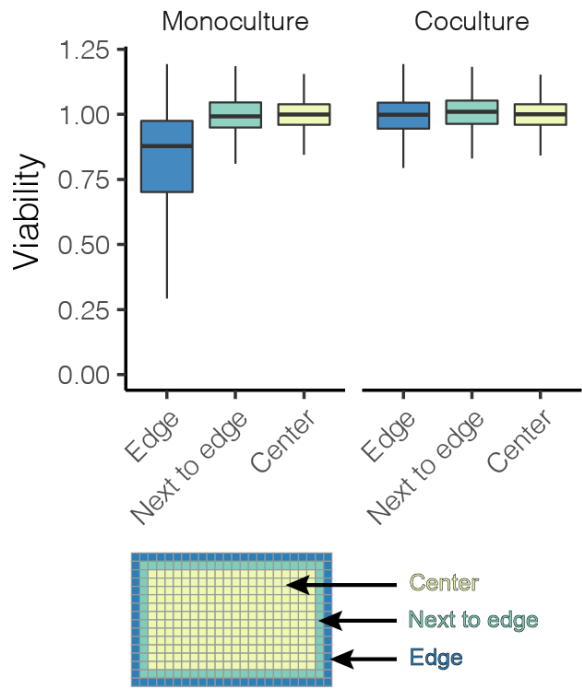

Figure 2: Spontaneous apoptosis in mono- and coculture screens.

A) Leukemia cell viability without drug treatment. Each point corresponds to a leukemia sample. $x$ - and $y$ - axes show median viabilities in mono- and coculture, with viability defined as the ratio of the viable cell count to the total cell count. The largest differences, and thus the strongest protection from spontaneous apoptosis, were observed in samples with low viability in monoculture. B) Plate positional effects in mono- and coculture. Viability without drug treatment is shown for three categories of wells, depending on their location on the 384-microwell plate. 
A

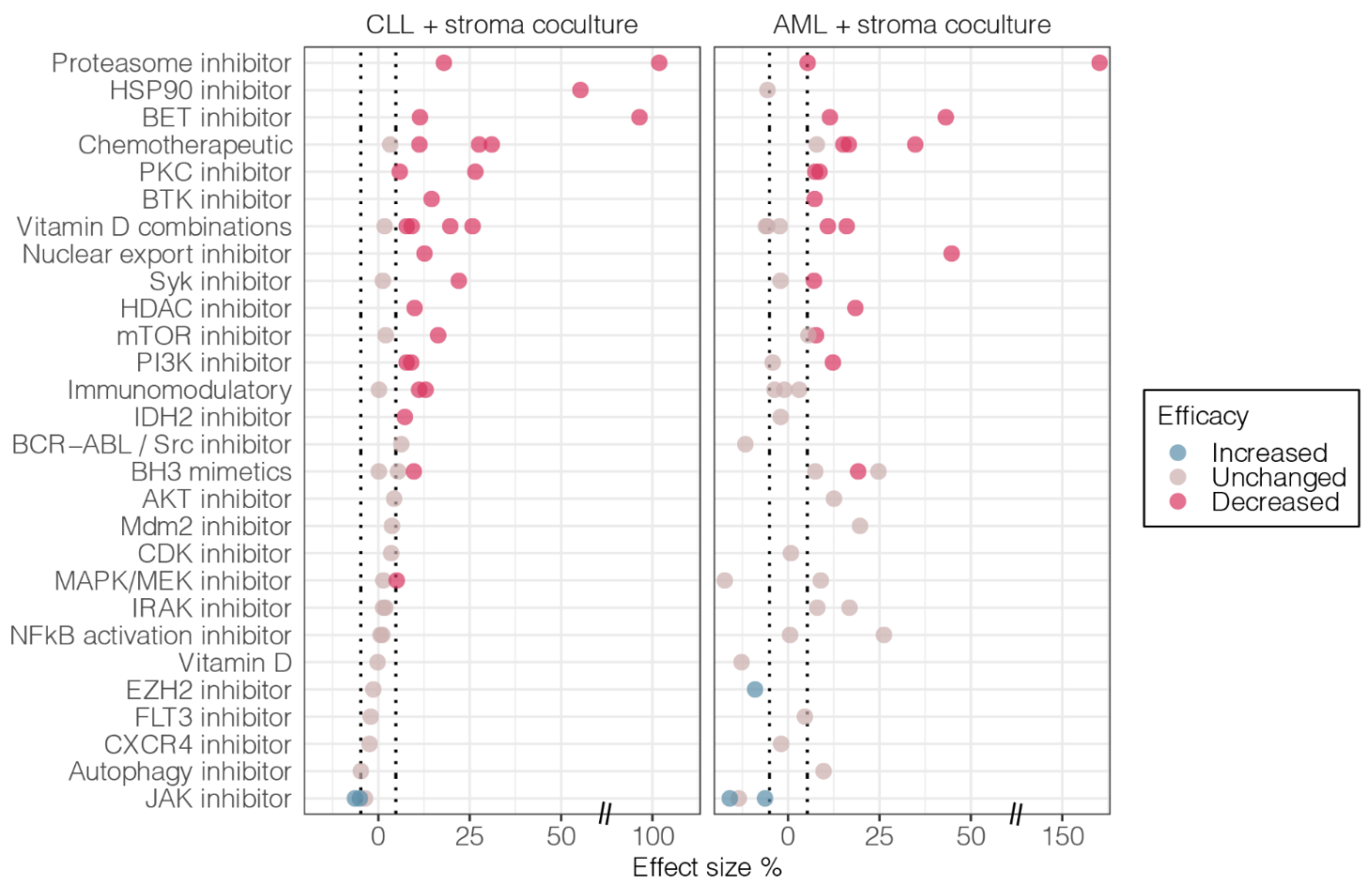

B

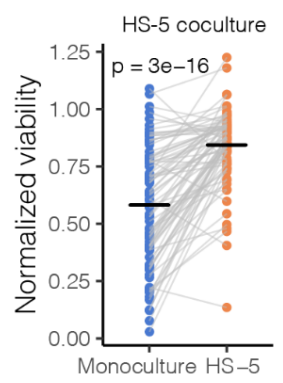

D

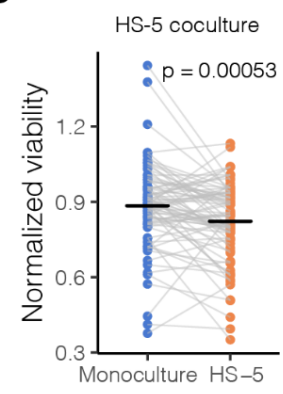

Fludarabine $0.6 \mu \mathrm{M}$

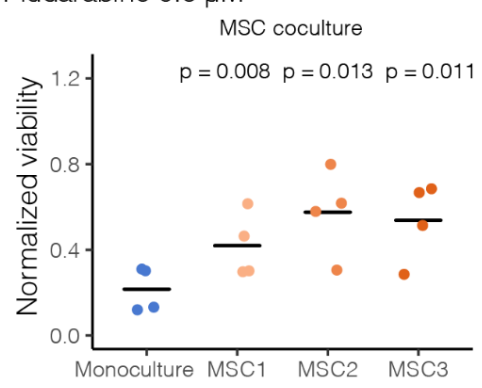

Ruxolitinib $9 \mu \mathrm{M}$

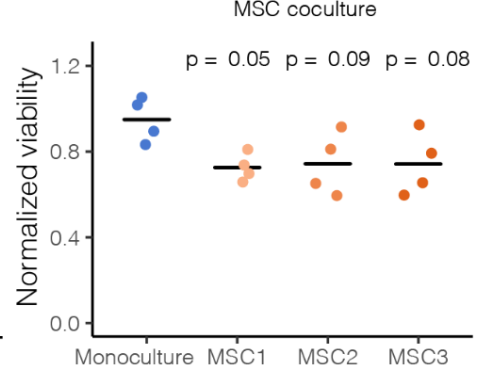

C

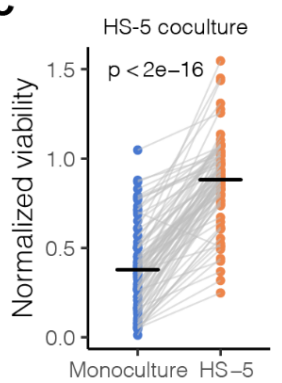

JQ1 $1.5 \mu \mathrm{M}$

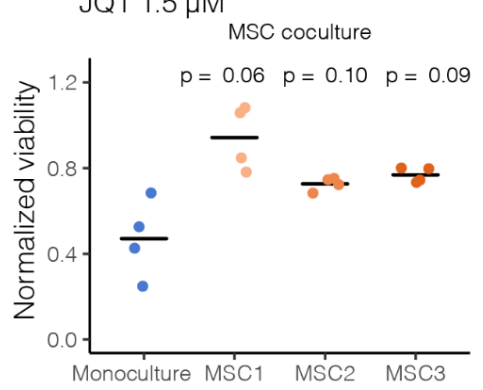

$\mathbf{E}$

Tofactinib $22.5 \mu \mathrm{M}$

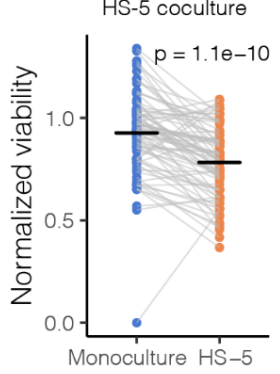

Figure 3: Stroma-mediated modulation of compound efficacy A) Compounds ordered by drug class and colored by their change in efficacy in CLL-stroma and AML-stroma coculture compared to monoculture. The $x$-axis shows the effect size of the drug response change relative to monoculture (see Materials and Methods). T-test was used to assess compound efficacy changes in coculture (FDR $=0.01$, see Materials and Methods). The effect size threshold of $5 \%$ is indicated (dotted vertical lines).

B)-E) Validation of the results from the HS-5 coculture screen in cocultures of CLL with primary mesenchymal stromal cells (MSCs). P-values compare the coculture mean with the reference value in monoculture. MSC1, MSC2, MSC3 were derived from 3 healthy donors. 
A
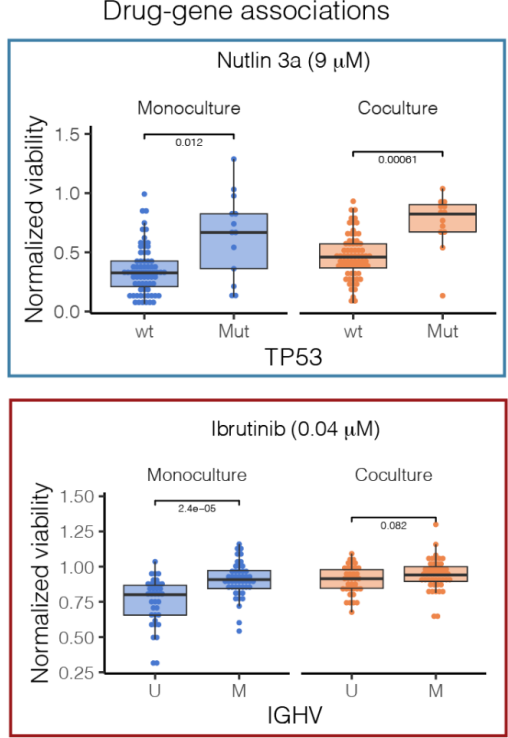

C

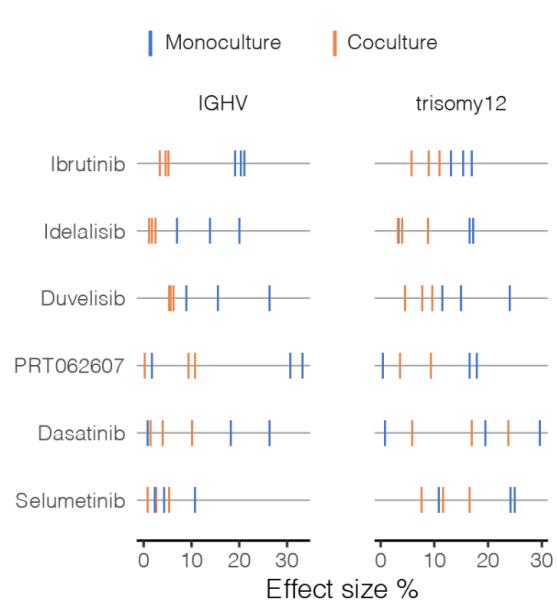

B

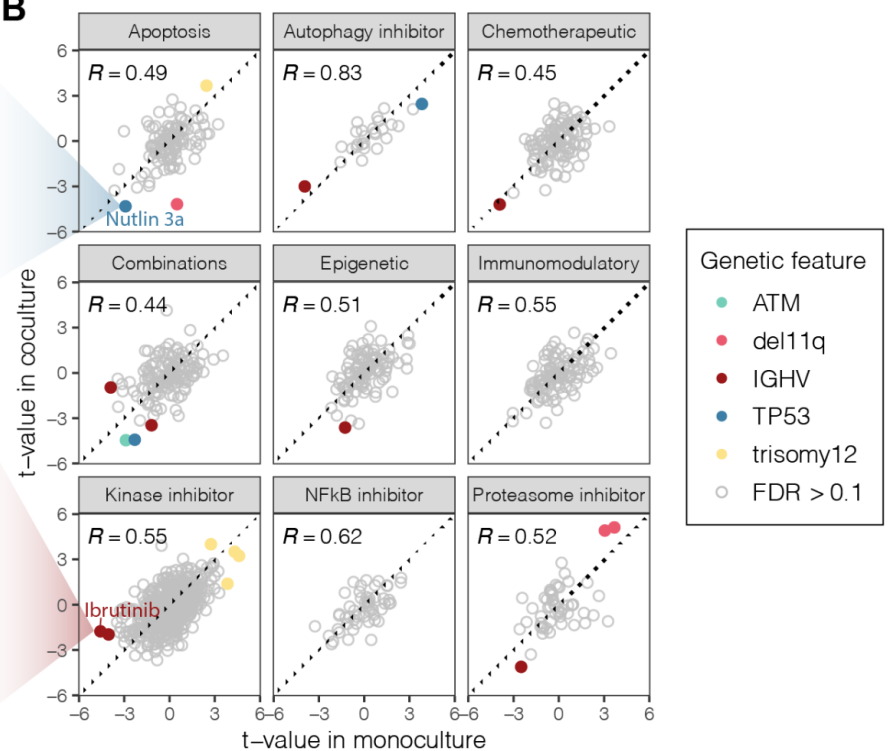

D

$\mathrm{BCR}$ inhibitor response

$\mathbf{E}$

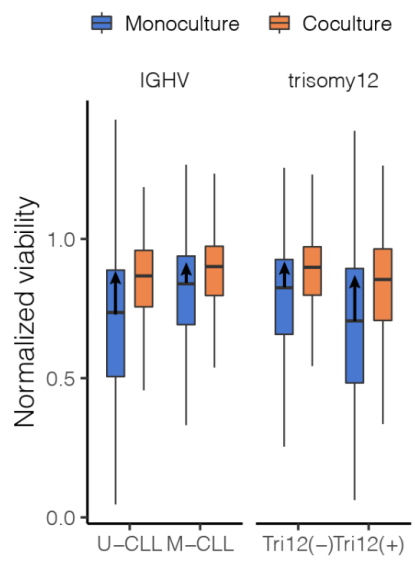

Drug response IQR

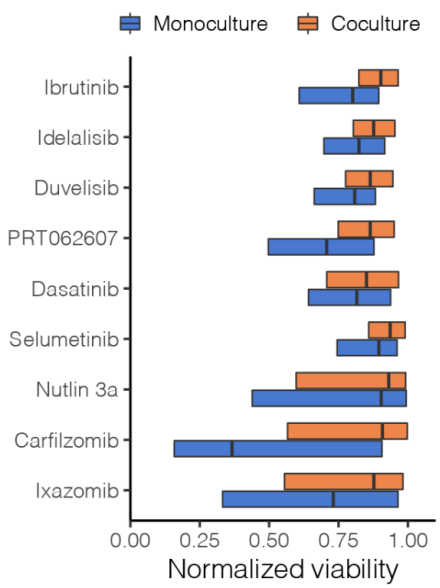

Figure 4: Drug-gene associations in coculture. A) Boxplots showing response to nutlin 3a and ibrutinib stratified by culture condition and mutational status. B) Comparison of drug-gene association statistics in mono- and coculture. The $x$ - and $y$-axes show the t-statistic values of drug-gene associations in mono- and coculture at a given concentration. C) Effect size of IGHV and trisomy 12 associations with B cell receptor (BCR) inhibitor response. The tick marks, colored by culture condition, show the absolute value of the effect size at 3 probed drug concentrations. D) The boxplots, colored by culture condition, show BCR inhibitor response stratified by IGHV mutational status (U-CLL / M-CLL) and trisomy12 (negative / positive). The arrows indicate differences between mono- and coculture medians, i.e. viability gain in coculture. E) Drug response variability in CLL samples treated with BCR inhibitors, nutlin $3 a$ and proteasome inhibitors stratified by culture condition. The boxplots compare the interquartile ranges (IQR) of drug sensitivities in mono- and coculture. 
bioRxiv preprint doi: https://doi org/10.1101/2022 02 18 481065. this version posted February 20, 2022. The copyright holder for this preprint (which was not certified by peer review) is the author/funder, who has granted bioRxiv a license to display the preprint in perpetuity. It is made available under aCC-BY-NC-ND 4.0 International license.
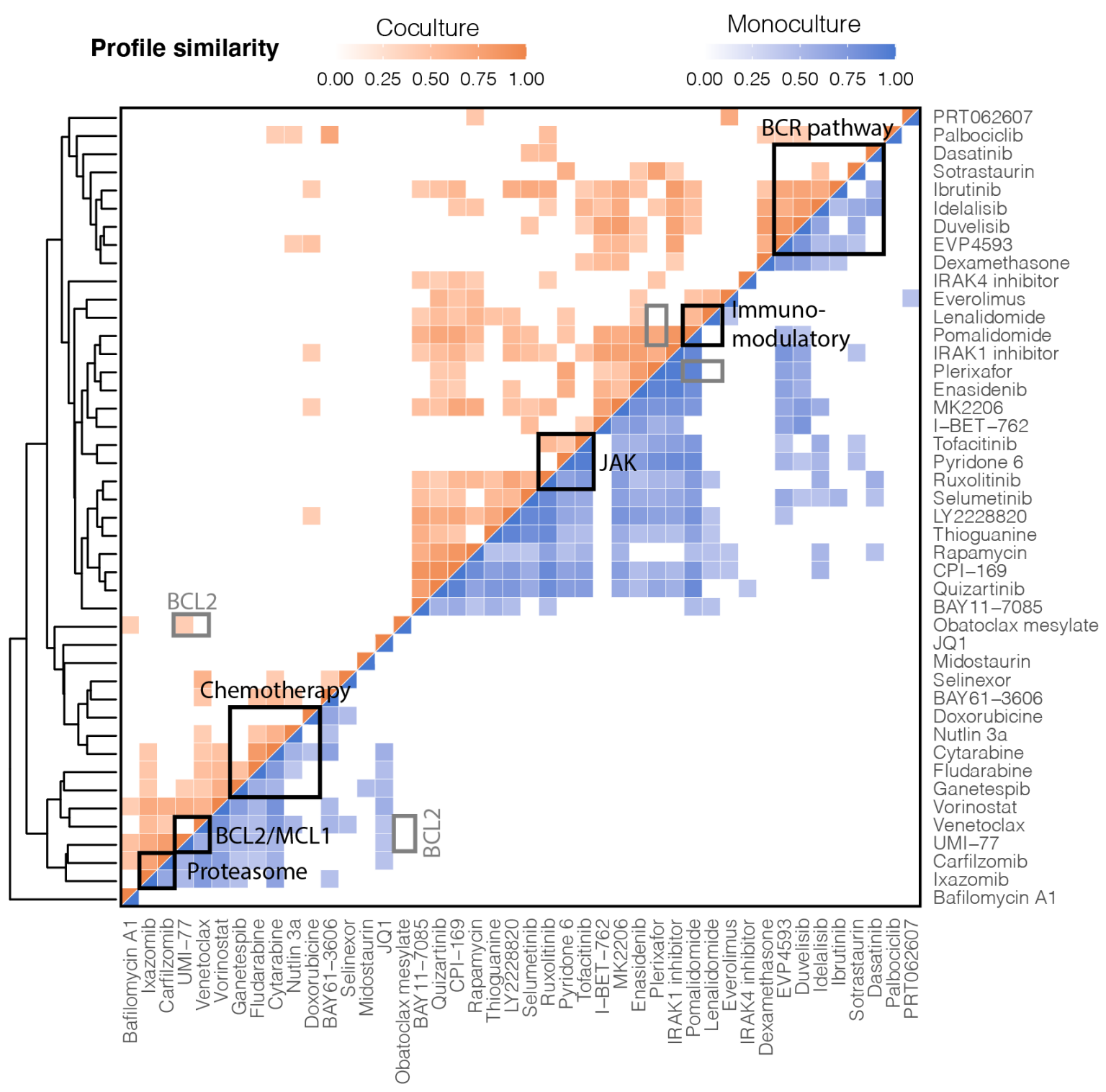

Figure 5: Compound similarity in mono- and coculture. Aggregated compound profiles were used to generate a hierarchical clustering of all probed compounds, excluding combinations (see Materials and Methods). Drug-drug correlations were computed separately in mono- and coculture (see Materials and Methods). Only high correlations ( $r$ > $0.4)$ are indicated in the heatmap. 


\section{Table 1}

\begin{tabular}{|c|c|c|}
\hline & Monoculture & Coculture \\
\hline Spontaneous apoptosis & $\begin{array}{l}(-) \text { Samples with low } \\
\text { viability }(<0.25) \text { present a } \\
\text { technical challenge }\end{array}$ & $\begin{array}{l}(+) \text { Low-viability samples } \\
\text { are rescued from } \\
\text { spontaneous apoptosis }\end{array}$ \\
\hline Plate-positional effects & $\begin{array}{l}\text { (-) Edge effect: edge wells } \\
\text { have systematically lower } \\
\text { viabilities }\end{array}$ & $(+)$ No edge effect \\
\hline Reproducibility & $(+)$ Good. cor $(r=0.92)$ & $(+)$ Good. cor $(r=0.88)$ \\
\hline Microenvironment effects & $\begin{array}{l}\text { (-) No signals from the } \\
\text { microenvironment }\end{array}$ & $\begin{array}{l}(+) \text { Ex-vivo model of the } \\
\text { bone marrow } \\
\text { microenvironment }\end{array}$ \\
\hline Drug sensitivity & $\begin{array}{l}(+) \text { Drug sensitivity } \\
\text { profiles can be used for } \\
\text { personalized medicine } \\
\text { (citations) }\end{array}$ & $\begin{array}{l}(++) \text { Drug sensitivity } \\
\text { profiles in presence of } \\
\text { microenvironment signals }\end{array}$ \\
\hline Drug-gene associations & $\begin{array}{l}(++) \text { Many drug-gene } \\
\text { associations are } \\
\text { correlated with the clinical } \\
\text { outcome }\end{array}$ & $\begin{array}{l}(+) \text { Direction of drug-gene } \\
\text { associations preserved. } \\
\text { Lower effect size } \\
\text { estimates. Variance } \\
\text { reduction enhances some } \\
\text { associations. }\end{array}$ \\
\hline Experimental complexity & $(+)$ Easy to handle & (-) More labor-intensive \\
\hline Image analysis & (+) Straightforward & $\begin{array}{l}\text { (-) Requires additional } \\
\text { staining or machine } \\
\text { learning to separate } \\
\text { cancer cells from stromal } \\
\text { cells }\end{array}$ \\
\hline
\end{tabular}

Table 1: Comparison of mono- and coculture: advantages and challenges. 